\title{
Watch Out-It's My Private Space! Examining the Influence of Technology Driven Intrusions on Employee Performance
}

\author{
Anuragini Shirish \\ Telecom School of Management \\ anuragini.shirish@telecom- \\ $\underline{\text { em.eu }}$
}

\author{
Shalini Chandra \\ S P Jain School of Global \\ Management \\ shalini.chandra@spjain.org
}

\author{
Shirish C. Srivastava \\ HEC, Paris \\ srivastava@hec.fr
}

\begin{abstract}
In this research we draw upon organizational literature on spatial intrusion to identify two components of technology related employee intrusion concerns -- employee accessibility and employee visibility. Situating our arguments in learning and control perspectives, we theorize the influence of employee 'accessibility' and 'visibility' on two technology enabled employee outcomes of productivity and innovation. We test the proposed research model through a survey of senior organizational managers who regularly use organizational technologies for executing their routine tasks. Results indicate that employee accessibility generally has positive while employee visibility has negative relationship with performance outcomes. Findings have significant implications for research and practice because they show that spatial intrusion does not necessarily have a negative influence on employee performance.
\end{abstract}

\section{Introduction}

The new digital era continues to usher in new ubiquitous technologies that allow organizations to conduct business transactions with ease and efficiency. Technologies such as smartphones and blackberries, by providing constant connectivity and communication, assist employees in getting immediate feedback on their tasks. Similarly, workflow and decision tracking technologies can help employees in accessing real-time guidance for performing their organizational tasks, thereby, keeping them productive, efficient and focused. Notwithstanding the assistance that such location and workflow tracking technologies provide to the employees, these technologies also provide employers with the ability to continuously monitor their employees' actions and behaviors. Though such a 'monitoring ability' afforded by the new organizational technologies can help improve efficiency, they can also be viewed by employees as an intrusion into their private space. This perceived spatial intrusion may generate negative employee views, adversely influencing their productivity and innovativeness. Given the increasing use of ubiquitous technologies with monitoring capabilities within organizations, it will be theoretically and practically interesting to examine the use of spatially intrusive technologies by organizations and their influence on employee related outcomes.

Recent review shows that past research has made significant strides in examining issues related to individuals' personal information such as the means and modalities for managing information access and control [12], yet two research gaps are particularly noteworthy- especially for the organizational context. First, the current organizational scenario is witnessing an unprecedented growth of ubiquitous spatially aware technologies that facilitate not only 24/7 employee accessibility but also continuous visibility of employees' tasks through workflow tracking technologies. The rampant use of such spatially intrusive technologies by organizations calls for a deeper understanding of the issue from a theoretical perspective [10]. Second, by facilitating continuous connectedness and allowing a wider range of monitoring practices for capturing and retrieving employees' work-related information, such information and communication technologies (ICTs) are expected to make the organization more efficient $[40,32]$ Yet, such pervasive technologies are instrumental in intruding into employees' private space by making their specific work processes traceable and by diminishing their work-home boundaries [2, 15, 9, 36]. However, there is very little research on the impact of the growing use of spatially aware technologies on employee performance thus far. Hence, we posit that in order to shield the organizational interest to use technologies to monitor the employees and at the same time protect the employee from over exposure, it is of prime importance to understand employee spatial intrusion concerns linked to their personal time and space. Examining such issues can help organizations formulate guidelines and policies for better 
management of their organizations and enhanced employee performance as well as theoretical inform research on spatial intrusion phenomenon.

Drawing from Cohen's (2008) concept of spatial privacy in networked organizations, we develop and validate a model that analyzes the effect of employee spatial intrusions on employee performance, specifically for employee productivity and innovativeness. Organizational technologies can cause spatial intrusion of employees in two ways: first, by increasing employee accessibility, i.e., by making employees reachable anytime and anywhere, and second, by increasing employee visibility, i.e., by making employees' work processes discernible and traceable. Building on the concepts of employee intrusions from organizational literature we seek first to conceptualize the components of employee spatial intrusion (ESI) concerns and then leveraging theories on learning and control, we theorize for the relationships of spatial intrusion concerns with the two technology enabled organizational objectives of employee productivity and employee innovation. The primary research questions addressed in this study are:

RQ1: Does employee spatial intrusion influence ICT enabled employee productivity?

RQ2: Does employee spatial intrusion influence ICT enabled employee innovation?

The present research makes two key contributions. First, contextualizing the concept of employee monitoring within organizations equipped with geospatial and pervasive technologies, this study conceptualizes employee spatial intrusion (ESI) (comprising employee accessibility and employee visibility). Second, grounding our arguments in organizational learning and control perspectives, the study theorizes and empirically tests the mechanisms describing the influence of spatial intrusion on employee productivity and innovation. The findings from this study can help organizations better understand employee spatial concerns and their impact on technology enabled employee performance.

\section{Background Literature and Theory}

\subsection{Employee Spatial Intrusion Concerns in Networked Organizations}

Current technologies with full geo-location and tracking capabilities threaten organizational employees with increased accessibility and visibility, resulting in more than their desired level of exposure during the conduct of their routine professional activities. For example, emerging location, communication and mobile technologies that are routinely used by employees, including global positioning systems (GPS), radio-frequency identification (RFID), and advanced wireless devices such as blackberries and smartphones, empower employers to locate and track their employees in real time and also to communicate with them continuously anytime and anywhere. Similarly, enterprise systems can be used to track employees' activities and decisions, providing employers with the continuous visibility of their employees' activities. Clearly, by leveraging such routine organizational technologies, employers are in a superior position to exercise control over their employees. Though such spatially aware technologies are embedded invisibly within the basic routine fabric of networked organizations, the associated intrusiveness in terms of employee accessibility and visibility challenges fundamental ideas about employees' personal space and time boundaries and the privacy expectations that accompany them. Through the use of such pervasive technologies, employers have the ability to track their employees' movements, actions and decisions, it can be viewed as the potential for directed surveillance and monitoring throughout the organizational environment and beyond [18]. These conditions of exposure could be categorized as employee regulation as opposed to enablement presenting itself as a coercive environment of managerial control as opposed to a caring one which can generate confirmatory employee behavior [38] and thus the response of the employee to such technologies becomes the critical factor [31].

Prior transparency studies have shown that visual monitoring of employees by their employers is viewed negatively by employees as an intrusion of their private space and does not contribute to positive organizational outcomes [13]. In a similar vein, Cohen (2008) introduced the concept of spatial privacy, showing that intrusion into employees' personal architectural space influences both job satisfaction and performance. But the extent of influence depends on the nature of the employees' tasks-for example, the influence of spatial privacy invasion is limited when it comes to the performance of routine menial tasks [45]. As senior leaders redesign their organizations to make organizational processes visible and transparent, advancements in technologies contribute to employees' concerns about sustaining their physical and personal space. In fact, threats to personal space from transparency become acute when visual surveillance and data-based surveillance are integrated. Though the spatial dimension of intrusion has been discussed in the field of law [15], it has not yet been explicitly examined in the organizational literature. Surveillance technologies are said not only to expose employees visually but also to unveil their online spaces, implying 
invasion into the material traces of their intellectual, emotional and relational movements [13, 15]. Therefore, it can be argued that because online activity happens in physical space, exposure of activities in networked work space alters employees' online conduct, and this in turn influences the continuing construction of self, place, community and performance within the networked space [15, 16]. Personal space is a resource for play, critical independence, tinkering and behavioral variations. Lack of control over personal space can weaken the capacity for democratic self-governance (as opposed to a modulated form of governance) and citizenship, which can affect the meaningful formation of agendas for human flourishing [15]. Ledema and Rhodes [31] in their study showed how health care professionals changed their behavioral norms (conceived as selfcare) in the presence of video surveillance installed in their work place. In this case, spatial intrusions lead to modulated self-governance as opposed to democratic self- governance that might have arisen in the absence the meditating intrusive technology. Hence, in the current era of emerging networked organizations, it becomes vital to re-examine the concerns of employees by explicitly theorizing for the influence of spatial intrusions.

\subsection{Conceptualizing employee spatial intrusion (ESI): accessibility and visibility}

As discussed in the preceding section, it is critical to understand the central spatial intrusion threats which are implicated by the new ubiquitous organizational technologies. From a theoretical perspective, such a study will help formulate the ESI concerns. From a practical standpoint, such a study can help organizations alleviate legal liability claims arising due to employee privacy violation and can also foster better participation of employees in organizational activities with a view to enhancing their productivity and innovation [40, 22]. Despite allusions in prior legal literature to concepts of spatial privacy, the discourse in the mainstream organizational literature on employee monitoring has not yet incorporated these key concepts. Additionally, very little research has examined the issue of ESI independently of the specific technology in use; the influence of organizational technologies generally on ESI has not yet been studied. Moreover, the discussion on ESI also relates to the question of how much technology intervention is actually good for an organization and its employees.

Motivated by these theoretical and practical dilemmas, the present study attempts to conceptualize ESI in the context of networked organizations and theorizes the mechanisms through which ESI influences the two key organizational objectives of technology enabled employee productivity and innovation [13]. We posit that examining the central spatial threats to intrusions implicated by emerging spatially-aware technologies will offer a nuanced understanding of employee monitoring. Consequently, leveraging Cohen's work we describe the spatial intrusion dimension for employees as consisting of concerns due to (1) employee accessibility (i.e., compromising employees' space and time boundaries by reaching the employee's personal space anytime and anywhere), and (2) visibility (i.e., making employees' behaviors, preferences and work processes discernible and traceable) [15].

Please note that accessibility and visibility are distinct and disjoint aspects of spatial intrusion for employees. For example, it is possible to make an employee accessible at all times through technologies, but they may not necessarily make the employee's work activities visible. Similarly, employee visibility can be deployed through enterprise systems that track and $\log$ detailed workflows, processes and decisions, but employees' accessibility through communication and collaboration technologies may be restricted. Thus, though both accessibility and visibility have the potential to invade employees' spatial arena, their specific influences on employee outcomes may be different because different levels of ESI may actuate different learning and control mechanisms between the employer and employees. Grounding the discussion in learning and control perspective and contextualizing it to specific employee outcomes, we theorize the influence of ESI enabled by organizational technologies.

\subsection{Organizational learning and control perspectives on employee spatial intrusion - accessibility and visibility}

Organizational learning is the process of creating, retaining, and transferring knowledge within an organization. The knowledge is created at four different levels: individual, group, organizational, and inter organizational. Organizational learning involves the process through which organizational units change as a result of experience. Individual learning is the smallest unit at which learning can occur [20]. Organizational technologies have the potential to both enable and disable organizational learning, which is largely oriented towards positive organizational change for improved organizational outcomes or even just continued existence. Thus, organizational learning rates are affected by improvements in an organization's 
technology, and improvements in the structures, routines and methods of coordination [8]. Huber (1991) identified four processes which contribute to organizational learning: knowledge acquisition, information distribution, information interpretation and organizational memory processes.

Before we discuss how 'accessibility' can influence the learning processes, it is useful to understand that the concept of locus of control in organizational literature. Locus of control describes if individual employees have control over their activities at work or they are controlled by outside forces such as employers [44]. Clearly, in the context of spatially aware networked organizations, the locus of control imbued by ICT-enabled accessibility- lies with both the employees and the employer - for accessing the required resources at their discretion. In the present context, employee accessibility through pervasive technologies can be envisioned to foster the four organizational learning processes. The first is by enabling communication, storage capability and interconnectivity amongst organizational employees it contributes to knowledge acquisition process [14]. The second is by enhancing knowledge sharing it facilitates information distribution process. The shared discretionary locus of control associated with accessibility helps improve expertise, experience and stored knowledge among employees as and when needed. This in turn increases the quantity and quality of knowledge transfer [12], shared understanding [11] and organizational learning curves [1] thereby impacting the third and fourth processes of information interpretation and organizational memory respectively. Hence, employee accessibility due to organizational ICTs that have a shared locus of control significantly influences organizational learning.

In addition to assuring employee accessibility, such technologies also contribute to employee 'visibility', makings employees' work processes observable and traceable for the employer. Enterprise-wide technologies can track and log detailed employee work processes, workflows and decisions. Moreover, there can be organizational technologies utilizing surveillance and monitoring techniques, including knowledge-search technologies and open communications of real-time data [13, 37]. However, all situations where organizational technologies make the employees' activities visible tantamount to increasing the employers' control over employees' work processes. In contrast to employee accessibility, the locus of control in this case is not shared and clearly rests with the employer. Because organizational technologies can make work processes visible, the locus of control over these activities is externalized, which can make employees insecure. Prior studies have identified this perception of external control as a key factor impacting employee well-being and performance negatively [23, 29, 39]. The threat of visibility due to organizational technologies can reduce employee perceptions of control over their environments and limit their capacity to control the information that might be available to their employers, leading to perceptions of monitoring and intrusion [7, 34]. Although visibility can contribute to some amount of organizational learning, especially for repetitive tasks, the threat to employees caused by their reduced perception of loss of their control can be detrimental for their motivation and performance.

In summary, in the current era of networked organizations, ICTs are increasingly being utilized with a view to improving employee innovation and productivity by refining the information flows and enabling knowledge creation. Such use of technologies definitely appears to enhance organizational learning, yet because of the increased monitoring capability, these technologies can also foster perceptions of reduced employee control over their organizational work processes and environment. This in turn can serve to demotivate employees and affect their performance adversely. Thus, organizational technologies that are implemented for improving their performance may lead to undesirable outcomes. In this research, situating our arguments in the organizational literature on learning and control, we theorize the mixed influence of organizational ICT-induced ESI on the two ICT-enabled employee outcomes of productivity and innovation.

\section{Hypotheses development}

The two ICT-enabled outcomes that we examine in this research-employee productivity and employee innovation-are clearly different in the organizational context. Productivity in the organizational context implies efficiency and standardization corresponding to productive conformance to standard practices, whereas innovation involves creating new things that may follow nonstandard practices and thus implies creative deviance. Because the model's two dependent variables are different, the influence of ESI (employee accessibility and employee visibility) and the associated mechanisms can be quite different for conforming to the assigned tasks (productivity), on the one hand, and creatively deviating from the task (innovation), on the other.

\subsection{Linking employee accessibility with technology-enabled employee outcomes}


Technologies used by employees at work such as blackberries and smartphones empower organizations to locate and track their employees in the real physical world anytime and anywhere, accurately, continuously and in real time. These technologies also empower employees by providing them with tools for accessing other employees as and when needed. We believe that this control - the ability to access employees-may often be desirable, as enhanced access would enable employees to be in continuous touch with the happenings in the organization, resulting in improved organizational learning [13]. In addition, better accessibility would improve the organizational processes by improving knowledge flows and sharing [13]. Greater employee accessibility would create a higher potential to increase the quantity and quality of knowledge transfer and shared understanding [8, 11] thereby accelerating the organizational learning curves [1] and resulting in higher technology-enabled productivity. Also, better employee accessibility resulting in enhanced mutual knowledge and the accessibility of others who can provide immediate feedback and improved accuracy of shared mental models increases employees' productivity in a technology-networked environment [19]. This is because increased employee accessibility can reduce lags between iterations at work, mitigate coordination problems and reduce social loafing [29], thereby increasing the productivity of computer-supported collaborative work through social facilitation. Hence, from a learning perspective, greater accessibility supports knowledge sharing and better information diffusion. Further, from the control perspective, there is a shared locus of control between the employer and the employee, and hence accessibility facilitates conformance to better standards and close monitoring. Because the locus of control is also with the employees, they can use accessibility selectively, resulting in greater employee productivity. Hence, we hypothesize:

Hla: In networked organizations, employee accessibility is positively associated with ICT-enabled employee productivity.

Furthermore, employees collaborating for work have a common reference point for discussion and a shared understanding for the development of the project. This keeps all employees on track with the latest happenings in the organization. Increased employee accessibility helps employees develop skills for problem solving and the ability to learn and innovate [48]. Thus, enhanced employee accessibility due to technologies diffuses the management function in new ways as employees organize and collaborate through technology for work. Also, ICT-enabled innovation grows due to the enhanced organizational learning as employees receive immediate feedback on their work, have real-time knowledge of each other's activities and are aware of each other's progress $[17$, 48]. This can enable faster cross-learning and building upon the work of others. Thus, due to enhanced learning, employees can be more innovative and create useful new products, services, ideas, procedures and processes by working together in the complex settings enabled by networked organizations. Hence, from a learning perspective, employee accessibility would be significantly related to enhancing innovation. Further, from a control perspective, the locus of control is with the employees as well as with the employer, so that employees have the liberty to share or build upon the knowledge of others in the organization as and when they need to do so. Past studies have shown that creativity amongst employees is enhanced when the locus of control is with them [30]. Therefore, an increased locus of control would also lead to enhanced innovation. Hence, we hypothesize:

Hlb: In networked organizations, employee accessibility is positively associated with ICT-enabled employee innovation.

\subsection{Linking visibility with technology- enabled employee outcomes}

Pervasive and ubiquitous technologies such as wi-fi and advanced cellular devices with tracking capabilities make details of information exchanges and employees' work processes visible. Moreover, routine enterprise systems in networked organizations have features that make employees' use of technologies and their work processes, workflows and decisions discernible and traceable. This visibility supports social inferences about what constitutes acceptable behavior for the employees within the organization. Organizations believe that visibility may enable operational control by ensuring access to richer, accurate and extensive real-time data by managers and employees, thus improving both hierarchical control and peer control [13, 37]. Consequently, many organizations are embracing ICT-enabled solutions to make their employees' work processes ever more visible. These include 'naked' communication of realtime data via advanced technologies and knowledgesearch technologies amongst others [37]. Such ICTenabled solutions can be helpful for standard repetitive tasks in two ways. First, from an organizational learning perspective, employees learn from others by simply observing. Second, from a control perspective, these standardized practices can be easily monitored by the supervisor and, additionally, there can be a social control mechanism whereby employees themselves can 
monitor and correct each other. Studies have shown that employees are more productive when they are watched by a productive peer [33] or by video monitoring [31]. As productivity in organizations is mainly related to standardized jobs with expected outcomes, we posit that for such jobs, employee visibility through technologies would enhance productivity by establishing productive conformance. Hence, we hypothesize:

H2a: In networked organizations, employee visibility is positively associated with ICT-enabled employee productivity.

In contrast to the preceding arguments for productivity associated with ICT-enabled innovation, employee visibility may also have a negative influence. Innovation in general is associated with creating new things, which requires creative deviance and risk taking and may lead to failure when trying out fresh alternatives [26, 42]. An environment imbued with employee visibility makes the employees and their actions more open to evaluation by managers and other organizational members [2]. Research on evaluation apprehension suggests that individuals often become worried when their work is being evaluated by others, more so if they are trying out new things. Thus, from a control perspective, the employees may not have a private creative space, and continuous evaluation may cause performance stress and inhibit them from taking risks [47]. Because the locus of control in the case of visibility is external to the employees, they may not be motivated to try new ideas. It has long been concluded that internal locus of control is said to aid creativity by enhancing the reliance on self and freedom from external control [35]. Alge et al. (2006) conceived information privacy as control over personal information and showed that this influences employee's psychological empowerment and leads to greater discretionary behaviors such as creative performance and innovation [5].

In addition to the control perspective, from the learning perspective, employees may not want to try out new things and will tend to conform to the observed learned behaviors and processes when s/he perceives that the technology has the potential to invade his/her personal space by making it visible to outsiders. As stated earlier, privacy perception is a resource for play, critical independence, tinkering and behavioral variations. Intrusion into the private space can weaken the capacity for self-governance weakening activities for human flourishing [15] such as constraining the scope for self-actualization through creative pursuits at work that may be viewed as learning at work. This may further inhibit innovation. Moreover, employee visibility may encourage employees to engage in hiding behaviors, especially if they intend to try something different, and thus the cognitive effort that would be spent in securing a personal space through hiding their tasks will also contribute to reducing their innovation performance $[13,43]$. Additionally, visibility will lead them to develop a tendency to share information only within their limited small groups, and consequently they may fail to secure the wisdom from large groups. In summary, from both learning and control perspectives, increased employee visibility would cause an increase in accountability, leading to greater conformity, a decline in risk taking and less creativity. This is because visible employees are likely to work in accordance with their group's expectations and to increase their conformity to the group's ideas and norms. Thus, the control due to technology-enabled visibility will hamper their creativity and consequent sharing of new innovative ideas, resulting in reduced learning and ICT-enabled innovation. Hence, we hypothesize:

$H 2 b$ : In networked organizations, employee visibility is negatively associated with ICT-enabled employee innovation.

\section{Method}

\subsection{Data Collection}

Survey method was used for collecting data and testing the proposed hypotheses. Validated scales from the existing literature were adapted to the research context to formulate the questionnaire. For measuring the items, we used a 7-point Likert scale. For example, ICT-enabled innovation and ICT-enabled productivity were adapted from Tarafdar et al. (2010). The ICTenabled innovation had scales like "ICT helps me to identify innovative ways of doing my job" and "ICT helps me to come up with new ideas relating to my job" The ICT-enabled productivity had scales such as "ICT helps me to improve my productivity." The two components of ESI defined as Accessibility and Visibility were adapted from Ayyagari et al. (2011). Accessibility had scales such as "The use of ICT enables others to have access to me" and "ICT make me accessible to others". Visibility has scales such as "It is easy for me to hide how I use ICTs" and "It is easy for me to hide my ICT usage" which were reverse coded.

Online questionnaires were sent via email to seniorlevel organizational managers who regularly use ICTs to accomplish their professional tasks. They were drawn from alumni lists of two business schools. The participation was voluntary in nature and confidentiality was guaranteed. A follow-up reminder 
was sent a week later, resulting in 185 responses, of which 163 were usable. We checked for outliers in our dataset by using Cook's distance statistic, and our analysis did not indicate any significant outliers. Hence, we analyzed all the usable responses to test our hypotheses. We observed that Cronbach's alpha for all research constructs ranged between 0.97 and 0.94 above the standard 0.70 , we concluded that the reliabilities for all constructs were adequate.

Control variables of four different types were included in the research model to account for alternative explanations, namely: (1) respondent demographics of age and gender (similar prior research has shown employee monitoring and intrusion concerns are dependent on demographics [3]) and for age, we used the number of years reported by the respondent and for gender, we used a dummy variable indicating male or female; (2) respondent experience: total work experience and work experience with the current employer measured by the number of completed years; (3) extent of ICT use, measured as the number of average hours of ICT use per week and (4) ICT self-efficacy, which has been found to be a significant variable influencing technology-related outcomes [49].

\subsection{Validity and Reliability}

We checked for three types of validity: content validity, convergent validity and discriminant validity. In this research, content validity was examined by first checking for consistency between the measurement items and the existing literature and then pre-testing the instrument.

The factor loading values of each of the construct in this research exceeded 0.50 , an acceptable minimum value. As the loadings within the construct were higher than those across constructs, this also demonstrated convergent validity. The composite reliability (CR) and the AVE (the ratio of the construct variance to the total variance among indicators) complied with the threshold of $0.70 \& 0.50$ respectively, thereby demonstrating convergent validity [25].

Since, the cross-loadings of the various constructs were quite low, it indicated discriminant validity [24]. As recommended [21], the values of the square root of the AVE (reported on the diagonals in Table 1 were all greater than the inter-construct correlations (the offdiagonal entries in Table 1) exhibiting further satisfactory discriminant validity. Table 1 provides the means, standard deviations and correlations for the research variables in the study.
Table 1. Descriptives and correlations

\begin{tabular}{|c|c|c|c|c|c|c|}
\hline & $\mathbf{M}$ & SD & ACCE & INOV & PROD & VISB \\
\hline ACCE & 5.74 & 0.10 & 0.96 & & & \\
\hline INOV & 5.05 & 1.31 & $0.31 * *$ & 0.95 & & \\
\hline PROD & 5.48 & 1.14 & 0.49 & $0.55 * *$ & 0.91 & \\
\hline VISB & 4.59 & 1.25 & 0.17 & $-0.18^{*}$ & 0.10 & 0.92 \\
\hline \multicolumn{7}{|c|}{$\begin{array}{l}* * \text { Correlation is significant at the 0.01 level; * Correlation is } \\
\text { significant at the } 0.05 \text { level (2-tailed) } \\
\text { Notes. ACCE: accessibility, INOV: innovation, PROD: } \\
\text { productivity, VISB: visibility. } \\
\text { M: Mean; SD: Standard Deviation. }\end{array}$} \\
\hline
\end{tabular}

\section{Results and Discussion}

\subsection{Demographics}

Analysis of the respondent demographics shows that almost $77 \%$ of the respondents in our sample were male. The average respondent age was 37.64 years (S.D. =6.75), and the respondents averaged 14.47 years (S.D. $=6.76)$ of total work experience and 7.17 years (S.D. =5.62) of experience with the current employer. This high level of work experience indicates that most respondents were working at senior managerial levels in their organizations. The average ICT use for professional work was 27.50 hours per week (S.D. $=18.27$ ).

\subsection{Hypothesis Testing}

Since both the dependent variables in this research measure ICT-enabled organizational outcomes, to allay the possibility of biased estimates using ordinary least squares, our model is estimated using seemingly unrelated regression (SUR) [42]. Specifically, a twostep hierarchical SUR model was used for testing the hypotheses. In the first step, we introduced all control variables, and in the second step, we introduced the two variables for ESI in networked organizations, namely, i.e., accessibility and visibility. Following the guidelines outlined [4], we mean-centered all values prior to hypothesis testing to reduce collinearity. We also checked for multicollinearity of our predictors and calculated the variance inflation factor (VIF), and found no significant multicollinearity problems [25]. The stepwise regression results for hypothesis testing are presented in Table 2.

Based on the results presented in Table 2, the control variables together explain $24.8 \%$ of the variance in productivity and $18.4 \%$ of the variance in innovation. Moreover, among the control variables, the variable measuring hours of ICT use per week has 
significant relationships with productivity $(\beta=0.013$, $\mathrm{p}<0.01)$ and innovation $(\beta=0.015, \mathrm{p}<0.01)$, and the variable measuring self-efficacy also has significant relationships with both productivity $(\beta=0.387, \mathrm{p}<0.01)$ and innovation $(\beta=0.326, p<0.01)$. The high explained variance by the control variables indicates a reasonable choice of controls in the research model.

Table 2. Results of seemingly unrelated regressions (SUR)

\begin{tabular}{|c|c|c|c|c|}
\hline & \multicolumn{2}{|c|}{ Productivity } & \multicolumn{2}{|c|}{ Innovation } \\
\hline & Step 1 & Step 2 & Step 1 & Step 2 \\
\hline & $\begin{array}{l}\text { Control } \\
\text { variables }\end{array}$ & $\begin{array}{l}\text { Main } \\
\text { effects }\end{array}$ & $\begin{array}{l}\text { Control } \\
\text { variables }\end{array}$ & $\begin{array}{l}\text { Main } \\
\text { effects }\end{array}$ \\
\hline & $\beta$ & $\beta$ & $\beta$ & $\mathrm{B}$ \\
\hline Constant & $\begin{array}{l}2.560^{* *} \\
(0.911)\end{array}$ & $\begin{array}{l}1.895^{*} \\
(0.906)\end{array}$ & $\begin{array}{l}3.765^{* *} \\
(1.094)\end{array}$ & $\begin{array}{l}4.202^{* *} \\
(1.098)\end{array}$ \\
\hline Age & $\begin{array}{l}0.029 \\
(0.032)\end{array}$ & $\begin{array}{l}-0.005 \\
(0.031)\end{array}$ & $\begin{array}{l}-0.010 \\
(0.039)\end{array}$ & $\begin{array}{l}-0.043 \\
(0.038)\end{array}$ \\
\hline Gender & $\begin{array}{l}-0.248 \\
(0.181)\end{array}$ & $\begin{array}{l}-0.254 \\
(0.171)\end{array}$ & $\begin{array}{l}-0.419 \\
(0.218)\end{array}$ & $\begin{array}{l}-0.408 \\
(0.208) \\
\end{array}$ \\
\hline $\begin{array}{l}\text { Total } \\
\text { work Exp }\end{array}$ & $\begin{array}{l}-0.016 \\
(0.034)\end{array}$ & $\begin{array}{l}0.013 \\
(0.033)\end{array}$ & $\begin{array}{l}-0.012 \\
(0.041)\end{array}$ & $\begin{array}{l}0.029 \\
(0.040)\end{array}$ \\
\hline $\begin{array}{l}\text { Exp with } \\
\text { current } \\
\text { employer }\end{array}$ & $\begin{array}{l}0.004 \\
(0.019)\end{array}$ & $\begin{array}{l}0.003 \\
(0.018)\end{array}$ & $\begin{array}{l}0.029 \\
(0.023)\end{array}$ & $\begin{array}{l}0.019 \\
(0.022)\end{array}$ \\
\hline $\begin{array}{l}\text { Hours of } \\
\text { ICT use } \\
\text { per week }\end{array}$ & $\begin{array}{l}0^{0.013}{ }^{* *} \\
(0.004)\end{array}$ & $\begin{array}{l}0.010^{*} \\
(0.004)\end{array}$ & $\begin{array}{l}0.015^{* *} \\
(0.005)\end{array}$ & $\begin{array}{l}\mathbf{0 . 0 1 3}^{*} \\
(0.005)\end{array}$ \\
\hline $\begin{array}{l}\text { Self- } \\
\text { efficacy }\end{array}$ & $\begin{array}{l}0.387^{* *} \\
(0.070)\end{array}$ & $\begin{array}{l}0.312^{* *} \\
(0.069)\end{array}$ & $\begin{array}{l}0.326^{* *} \\
(0.085)\end{array}$ & $\begin{array}{l}0.272^{* *} \\
(0.084)\end{array}$ \\
\hline ACCE & & $\begin{array}{l}0.361^{* *} \\
(0.081)\end{array}$ & & $\begin{array}{l}0.295^{* *} \\
(0.099)\end{array}$ \\
\hline VISB & & $\begin{array}{l}-0.009 \\
(0.061) \\
\end{array}$ & & $\begin{array}{l}-0.235^{* *} \\
(0.074) \\
\end{array}$ \\
\hline $\mathrm{R}^{2}$ & $0.248^{* *}$ & $0.330^{* *}$ & $0.184^{* *}$ & $0.258^{* *}$ \\
\hline$\Delta \mathrm{R}^{2}$ & & $0.082^{* *}$ & & $0.074^{* *}$ \\
\hline $\begin{array}{l}\text { Chi- } \\
\text { square }\end{array}$ & $\mathbf{5 3 . 9 8 0}$ & 80.210 & 36.860 & 56.740 \\
\hline P Value & 0.000 & 0.000 & 0.000 & 0.000 \\
\hline $\begin{array}{l}\text { Notes: Sig } \\
\text { Figures in } \\
\text { level; * } p \\
\text { Notes. AC }\end{array}$ & $\begin{array}{l}\text { ficant figur } \\
\text { arentheses } \\
0.05 \text { level. } \\
\text { E: accessib }\end{array}$ & $\begin{array}{l}\text { are show } \\
\text { e standar } \\
\text { ty, VISB: }\end{array}$ & $\begin{array}{l}\text { in boldface } \\
\text { errors. ** } \\
\text { isibility }\end{array}$ & $\begin{array}{l}n=163 . \\
=0.01\end{array}$ \\
\hline
\end{tabular}

Upon incorporating the hypothesized effects of accessibility and visibility variables into the regression equation (step 2, main effects model), we observe a significant change in variance $\left(\Delta \mathrm{R}^{2}\right): \quad 8.2 \%$ (productivity) and $7.4 \%$ (innovation), compared to variance explained by the model's control variables. We also observe that accessibility significantlyinfluences both productivity $(\beta=0.359$, $\mathrm{p}<0.01)$ and innovation $(\beta=0.264, p<0.01)$, thereby supporting $\mathrm{H} 1 \mathrm{a}$ and $\mathrm{H} 1 \mathrm{~b}$. On the other hand, visibility is not significantly related to productivity $(\beta=-0.005$, ns) but has a significant negative relationship with innovation $(\beta=-0.195, \mathrm{p}<0.01)$. Thus, $\mathrm{H} 2 \mathrm{a}$ is not supported while $\mathrm{H} 2 \mathrm{~b}$ is supported.

We had expected that visibility would be positively associated with ICT-enabled productivity (H2a). The non-support of this hypothesis is possibly because even though better learning of standardized jobs is facilitated by visibility, employees may experience cognitive overload causing stress, thus limiting employees' learning outcomes, increasing mistakes and hampering productivity [47]. The possibility of close evaluation and monitoring, due to visibility may weaken the employees' initiative, and thus negatively influence productivity [48]. Thus, we observe that visibility seems to have mixed effects which influences productivity not only positively (as discussed in the argument for H2a) but also negatively. Because of both positive and negative influences of visibility on ICTenabled employee productivity, the relationship is nonsignificant.

\section{Implications}

\subsection{Theoretical Implications}

First, though technological intrusions distract the employees and entice them to stray from their duties, not many studies in organizational literature have examined this phenomenon. Building on Cohen's (2008) spatial privacy concepts, the present research proposes and empirically tests ESI concerns in the context of networked organizations. By contextualizing the concept of spatial intrusion within ICT-networked organizations, this study is one of the first to conceptualize and examine the dimensions of ESI concerns related to the increasing use of spatially aware organizational ICTs. Specifically, leveraging literature on architectural and spatial intrusion in the physical world [15], this study specifies two dimensions of ESI in ICT-networked organizational environments: employee accessibility and employee visibility. This extension of the ESI concept is a significant contribution to the organizational and IS literature as it opens avenues for explicitly considering ESI in the present technologically enabled organizational environments. The study also suggests context-specific theorization for better understanding ESI concerns in different contexts [28]

Second, situating our arguments in organizational learning and control perspectives, the study theorizes and empirically tests the mechanisms describing the influence of ESI on ICT-enabled employee productivity and innovation. We provide theoretical reasoning for the distinction we find between the two 
employee related outcomes of productivity and innovation determined by the influence of ESI. The mechanisms explained through learning and control perspective can guide future research on spatial intrusion phenomenon.

Third, this study clearly demonstrates that the factors constituting ESI concerns may have different impacts on different outcomes. Spatial intrusion cannot be judged to be universally bad (or good). ESI due to technology may support certain outcomes and may not support others, depending on employees' perceptions of their control over such invasive practices. Yet the boundary conditions and the optimal amount under which the impact of spatial infringement is viewed favorably $[41,6]$ remains to be empirically determined and is thus a ripe topic for future research.

\subsection{Practical Implications}

First, employee intrusions - specifically, ESI-has not been examined extensively in organizational literature. In the context of present-day ICT-networked organizational environments, it is imperative to explicitly examine the role of the spatial dimension of employee intrusions, and this study is one of the first modest steps in that direction. It informs practitioners about the key role that spatial intrusions can play in effectuating employee outcomes, which needs to be explicitly considered during the formulation of organizational policies. The study can benefit the domain of managerial practice by helping managers strategize their employee intrusion and monitoring policies based on their targeted employee outcomes.

Second, the results from this study highlight that ESI does not have a universally accepted unfavorable impact. ESI of certain kinds might be acceptable to employees and can have a positive influence on certain outcomes for both employees and organizations. However, spatial intrusions are highly contextual thus visibility and accessibility can have detrimental effects and individuals might be keen to seek control over this intrusion. For example, while using ICT tools such as instant messaging (IM), users can control their visibility by displaying their desired status (even as being offline). Thus, providing the perception of a shared locus of control between the employer and the employee, may lead to win-win situation at work. Organizational goals and user's needs and perceptions can both inform technology design initiatives in the context of spatially aware technologies.

\section{References}

[1] Adler, P.S., and Clark, K.B. 1991. "Behind the Learning Curve: A Sketch of the Learning Process," Management Science (37:3), pp.267-281.

[2] Ahuja, M., and Galvin, J. 2007. "Socialization in Virtual Groups," Journal of Management (29:2), pp. 161-185.

[3] Ahuja, M., and Thatcher, J. 2005. "Moving beyond Intentions and toward the Theory of Trying: Effects of Work Environment and Gender on Post-Adoption Information Technology Use," MIS Quarterly (29:3), pp. 427-459.

[4] Aiken, L.S., and West, S.G. 1991. Multiple Regression: Testing and Interpreting Interactions, Sage, Newbury Park, California.

[5] Alge, B.J., Ballinger, G.A., Tangirala, S., and Oakley, J.L. 2006. "Information Privacy in Organizations: Empowering Creative and Extrarole Performance," Journal of Applied Psychology (91:1), pp.221-232.

[6] Altman, I. 1975. The Environment and Social Behavior: Privacy, Personal Space, Territory and Crowding, Brooks/Cole, Monterey, California.

[7] Ambrose, M.L., Alder, G.S., and Noel, T.W. 1998. "Electronic Performance Monitoring: A Consideration of Rights," In Managerial Ethics: Moral Management of People and Processes (Schmink M, Ed), pp 61-80, Lawrence Erlbaum, Mahwah, New Jersey.

[8] Argote, L. 2012. "Organizational learning: Creating, retaining and transferring knowledge", Springer Science \& Business Media.

[9] Ayyagari, R., Grover, V., and Purvis, R. 2011. "Technostress: Technological Antecedents and Implications," MIS Quarterly (35:4), pp.831-858.

[10] Ball, K., Daniel, E.M., and Stride, C. 2012. "Dimensions of Employee Privacy: An Empirical Study," Information Technology \& People (25:4), pp.376394.

[11] Bechky, B.A. 2003. "Sharing Meaning across Occupational Communities: The Transformation of Understanding on a Production Floor," Organization Science (14:3), pp.312-330.

[12] Bélanger, F., and Crossler, R.E. 2011. "Privacy in the Digital Age: A Review of Information Privacy Research in Information Systems," MIS Quarterly (35:4), pp.1017-1042.

[13] Bernstein, E.S. 2012. "The Transparency Paradox: A Role for Privacy in Organizational Learning and Operational Control," Administrative Science Quarterly (57:2), pp.181216.

[14] Büchel, B., and Raub, S. 2003. "Media Choice and Organizational Learning," In Handbook of Organizational Learning and Knowledge (Dierkes M, Antal AB, Child J and Nonaka I), New York: Oxford University Press, Inc, pp. 518534.

[15] Cohen, J.E. 2008. Privacy, Visibility, Transparency, and Exposure, The University of Chicago Law Review (75:1), pp.181-201.

[16] Costas, J., and Grey, C. 2014. "Bringing Secrecy into the Open: Towards a Theorization of the Social Processes of Organizational Secrecy", Organization Studies, (35:10), pp. 1423-1447. 
[17] Cummings, J. 2011. "Geography Is Alive and Well in Virtual Teams," Communications of the ACM (54:8), pp.2426.

[18] Dodge, M., Batty, M., and Kitchin, R. 2004. "No Longer Lost in the Crowd: Prospects of Continuous Geosurveillance," Presented at Association of American Geographers Annual Conference, Philadelphia.

[19] Dourish, P. and Bellotti, V. 1992. "Awareness and Coordination In Shared Workspaces," In Proceedings of the 1992 ACM Conference on Computer-Supported Cooperative Work, pp.107-114.

[20] Fiol, C.M., and Lyles, M.A. 1985. "Organizational Learning," Academy of Management Review (10:4), pp.803813.

[21] Fornell, C., and Larcker, D.F. 1981. "Structural Equation Models with Unobservable Variables and Measurement Errors," Journal of Marketing Research (18:3), pp.39-50.

[22] Friedman, B.A., and Reed, L.J. 2007. "Workplace Privacy: Employee Relations and Legal Implications of Monitoring Employee E-Mail Use," Employee Responsibilities and Rights Journal (19:2), pp.75-83

[23] Ganster, D.G., and Fusilier, M.R . 1989. "Control in the Workplace," In International Review of Industrial and Organizational Psychology (Gooper CL and Robertson IT, Eds), pp. 235-280, Wiley, Chichester, England.

[24] Gefen, D., and Straub, D.W. 2005. "A Practical Guide to Factorial Validity Using PLS-Graph: Tutorial and Annotated Example," Communications of the Association for Information Systems (16:5), pp. 91-109.

[25] Hair, J.F., Black, W.C., Babin, B.J., Anderson, R.E., and Tatham, R.L. 2006. Multivariate Data Analysis, 6th Ed, Pearson Prentice Hall, Upper Saddle River, New Jersey.

[26] Hansen, M.T., and Birkinshaw, J. 2007. "The Innovation Value Chain," Harvard Business Review (85:6), pp.121-130.

[27] Huber, G.P. 1991. "Organizational Learning: The Contributing Processes and the Literatures," Organization Science (2:1), pp.88-115.

[28] Johns, G. 2006. "The Essential Impact of Context on Organizational Behavior," Academy of Management Review (31:2), pp.386-408.

[29] Karau, S.J., and Williams, K.D. 1993. "Social loafing: a meta-analytic review and theoretical integration," Journal of Personality and Social Psychology (65:4), pp.681-706.

[30] Lally, L. 1996. "Privacy versus Accessibility: The Impact of Situationally Conditioned Belief," Journal of Business Ethics (15:11), pp.1221-1226.

[31] Ledema, R., and Rhodes, C. 2010. "The Undecided Space of Ethics in Organizational Surveillance," Organization Studies (31:2), pp.199-217.

[32] Lipford, R.H., Wisniewski, J.P., Lampe, C., Kisselburgh, L., and Caine, K. 2012. "Workshop on Reconciling Privacy with Social Media," Proceedings of the ACM Conference on Computer Supported Cooperative Work, Seattle.

[33] Mas, A., and Moretti, E. 2009. "Peers at Work," American Economic Review (99:1), pp.112-145.

[34] Paschal, J.L., Stone, D.L., Eugene, F., and StoneRomero, E.F. 2009. "Effects of Electronic Mail Policies on
Invasiveness And Fairness," Journal of Managerial Psychology (24:6), pp.502-525.

[35] Rogers, C. R. (1954). Toward a theory of creativity. ETC: A review of general semantics, 249-260.

[36] Sarker, S., Xiao, X., Sarker, S., and Ahuja, M. 2012. "Managing Employees' Use of Mobile Technologies to Minimize Work-Life Balance Impacts," MIS Quarterly Executive (11:4), pp.143-157.

[37] Sewell, G. 1998. "The Discipline of Teams: The Control of Team-Based Industrial Work Through Electronic and Peer Surveillance," Administrative Science Quarterly (43:2), pp.397-428.

[38] Sewell, G., and Barker, J.R. 2006. "Coercion Versus Care: Using Irony to Make Sense of Organizational Surveillance," Academy of Management Review (31:4), pp.124.

[39] Sipior, J.C., Ward, B.T., and Rainone, S.M. 1998. "Ethical Management of Employee E-Mail Privacy," Information Systems Management (15:1), pp.41-47.

[40] Smith, W.P., and Tabak, F. 2009. "Monitoring Employee E-Mails: Is There Any Room for Privacy?," The Academy of Management Perspectives (23:4), pp.33-48.

[41] Snyder, J.L. 2010. "E-Mail Privacy in the Workplace: A Boundary Regulation Perspective," Journal of Business Communication (47:3), 266-294.

[42] Srivastava, S.C., and Teo, T.S.H. 2012. "Contract Performance in Offshore Systems Development: Role of Control Mechanisms," Journal of Management Information Systems, (29:1), pp.115-158.

[43] Srivastava, S.C., Mithas, S., and Jha, B. 2013. "What Is Your Global Innovation Strategy?," IT Professional (15:6), pp.2-6.

[44]Spector, P.E., and O'Connell, B.J. 1994. "The Contribution of Personality Traits, Negative Affectivity, Locus of Control and Type A to the Subsequent Reports of Job Stressors and Job Strains," Journal of Occupational and Organizational Psychology (67:1), pp.1-11.

[45] Sundstrom, E., Burt, R.E., and Kamp, D. 1980. "Privacy at Work: Architectural Correlates of Job Satisfaction and Job Performance," Academy of Management Journal (23:1), pp.101-117.

[46] Tarafdar, M., Tu, Q., and Ragu-Nathan, T.S. 2010. "Impact of Technostress on End-User Satisfaction and Performance," Journal of Management Information Systems (27:3), pp.303-334.

[47] Thompson, L.F., Sebastianelli, J.D., and Murray, N.P. 2009. "Monitoring Online Training Behaviors: Awareness of Electronic Surveillance Hinders E-Learners," Journal of Applied Social Psychology (39:9), pp.2191-2212.

[48] Torkzadeh, G., and Doll, W.J. 1999. "The Development of a Tool for Measuring the Perceived Impact of Information Technology on Work," Omega International Journal of Management Science (27:3), pp.327-339.

[49] Venkatesh, V., Morris, M.G., Davis, G.B., and Davis, F.D. 2003. "User Acceptance of Information Technology: Toward a Unified View," MIS Quarterly (27:3), pp.425-478. 